\title{
A Sintaxe da Janela
}

\author{
Luís Antônio Jorge
}

\begin{abstract}
Resumo
A preocupaçāo fundamental do trabalho é de caráter ontológico: esboçar o problema das significações apriorísticas e autônomas dos elementos que compõem a sintaxe arquitetônica.

O trabalho elege um desses elementos: a janela. Este artigo parte da aproximaçāo histórica entre a janela e a secçāo da pirâmide visual, construção imaginária da teoria da perspectiva renascentista.

A consideraçāo da janela na linguagem arquitetônica implica reconhecer uma ambigüidade essencial: a janela deve inserir-se ordenadamente no plano da parede - raciocínio típico da modenatura - mas também relacionar-se com a imagem vista através dela, que extrapola o plano, ressaltando a tridimensionalidade - herança da perspectiva renascentista, fundamentada no espaço euclidiano. Ver janela ou ver através da janela são alternativas que se colocam tanto ao observador interno ao edifício, quanto ao externo. Texto de duplaface, a sintaxe da janela versa sobre o relacionamento desses dois lados.
\end{abstract}

\section{Abstract}

The work's fundamental concern has an ontological character: to sketch the problem of the primordial and autonomous significations of the architectural syntax elements.

The work chooses one of these elements: the window. It starts from the historical approximation between the window and a section of the visual pyramid, an imaginary construction of the renaissantist perspective theory.

The window, in the architectural language, implies in the acknowledgment of an essential ambiguity: the window must insert itself in an orderly manner into the wall's plan - a typical reasoning of the modénature - and at the same time relate itself with the image seen through it. beyond its own plan, putting in evidence the three-dimensionality, heritage of the renaissantist perspective, fundamented on the Euclidean space. To see the window or to see through the window are alternatives that are available both to the observer inside the building as much as to the external one. Double-faced text, the window's sintax deals with the relationship of both of these sides.
Artigo extraído da Dissertaçâo de Mestrado "A Sintaxe da Janela" apresentada em maio de 1993

Orientador: Prof. Dr. Décio Pignatarl 


\section{A Sintaxe da Janela}

Nāo vês que o olho abraça a beleza do mundo inteiro?... É janela do corpo humano, por onde a alma especula e frui a beleza do mundo, aceitando a prisão do corpo que, sem esse poder, seria um tormento... Ó admirável necessidade! Quem acreditaria que um espaço tāo reduzido seria capaz de absorver as imagens do universo?

\section{Leonardo da Vinci}

A construção da perspectiva onilocular e central, a partir de um método lógico e abstrato, interrompe a progressāo representativa do espaço simbólico dos antigos, e funda uma "construçāo espacial unitária e não-contraditória, de extensão infinita"1 As palavras de Alberti consagram a analogia que enlaça olho e janela: "o quadro (da pintura) é uma janela transparente pela qual nós vislumbramos uma seçāo do mundo visivel" Através desta analogia de natureza sintática introduz-se a janela no mundo da linguagem arquitetônica

A analogia entre a secçāo da pirâmide visual e a imagem vista da janela, mais que uma metáfora que enlaça olho e janela, possui um profundo sıgnificado para a história da janela, na medida em que ela oferece à janela um papel essencial na sintaxe arquitetônica. Poderiamos dizer que essa analogia define um universo de investigação, ao sugerir que o plano no qual se representa o novo domínio da representação espacial, seja o mesmo plano contido na moldura da janela. Ou seja, o aparecimento da janela no universo da linguagem arquitetônica, confunde-se com o esforço de sistematização dos conhecimentos matemáticos para a racionalizaçāo $e$, conseqüentemente, representação do espaço através da perspectiva. Nesse sentido, a sua origem relaciona-se inexoravelmente a um momento muito especial da história da Arquitetura: a Renascença, onde, segundo Wittkower ${ }^{2}$ a "comensurabilidade da medida era o ponto nodal" dos valores estéticos. A mediçāo, a comensurabilidade das dimensōes, permitia o acesso ao conhecimento que regia a ordem das coisas, a relação entre as partes, assim como. entre as partes e o todo.

Os primórdios da sintaxe da janela. o ingresso da janela no mundo da linguagem da arquitetura, define-se como o momento da tomada de consciência de que a janela era abertura para um espaço que se pretendia objetivado. A arquitetura descobria um mecanismo, um instrumento ordenador que transcendia o seu domínio no âmbito do espaço fechado. isto é, do seu interior, onde podia exercer controle absoluto, para atingir, de uma maneira mais contundente, o espaço exterior, para onde ela dirigia o seu olhar. Olhar representativo de uma maneira profundamente estetizada de construção do espaço, mas também, olhar de um homem que se supunha no centro do universo.

Essa estetizaçāo refere-se à racionalização do espaço no Renascimento ou, se preferirmos, a um espaço visual de dimensões mensuráveis; refere-se também "a quais distâncias entre objetos vistos por um observador podem representar-se em uma superfície de duas dimensōes e com uma exatidão matemática" ${ }^{\prime 3}$ Como bem demonstrou Panofsky, essa exatidão matemática não era somente a garantia de correção, de objetividade, do triunfo da vontade de poder humano para anular as distâncias, mas também, e talvez mais ainda, uma garantia de perfeiçāo estética, uma satisfaçāo intelectual para os novos anseios de exatidão e previsibilidade. A perspectiva oferecia à mente e aos olhos, a oportunidade de relacionar as coisas no espaço. de unir as partes da paisagem. 
A janela é moldura, mas também perspectiva. A janela ao delimitar o campo de visão e situar o observador, fundia o espaço bidimensional da moldura ou do plano de representaçāo com o espaço tridimensional, real ou imaginário representativo de um olhar extremamente idealizado e auratizado: a imagem correta, ordenada, hierarquizada, mensurável e harmônica da pintura. Na origem sintática da janela está o enquadramento ideal da pintura renascentista e a herança pitagórico-platônica da harmonia existente nas regras das proporçōes, onde a busca dos valores estéticos, passava por uma perfeita tradução do mundo cristalino e verdadeiro do intelecto.

As regras da sintaxe clássica estabeleceram o tipo de implantação das janelas. Obviamente as janelas são áreas de fragilização da estrutura da edificação, já que não suportam cargas. Sendo assim, elas só poderiam se situar entre as colunas (ou pilares) que exerciam exatamente esse papel. Segundo as regras clássicas, os tipos de espaçamento entre as colunas, o intercolúnio ${ }^{4}$ variavam numa relação com o diâmetro e a altura das colunas.

As janelas se subordinarão a estas regras, à hierarquia das ordens, inserindose sempre simetricamente num intercolúnio. A sua tarefa era, para usarmos o termo preciso, o desenvolvimento da arte da modenatura, a arte de traçar perfis e ordenar molduras "numa disposição harmoniosa sobre as superfícies arquitetônicas, em funçāo de seus efeitos estéticos que acompanham sempre o jogo de luzes e de sombras que elas provocam, exatamente no local onde sāo aplicadas" ${ }^{5}$, o que implica, também, um determinado jogo de significados. As janelas serão guarnecidas por uma moldura denominada edícula, que consiste numa segunda ordem com poder de, na maioria das vezes, demonstrar metonicamente o princípio geral do edifício. Assim sendo, embora a janela se introduza como um elemento a mais numa linguagem predefinida, desde já pode-se observar que ela tem o poder de aglutinar informaçāo, de ser alvo e foco, de possuir alta densidade sígnica; uma eloqüência informacional, um potencial metonimico ou sugestivo.

\section{A Janela e o Tempietto de Bramante}

Donato Bramante foi um arquiteto que levou às últimas conseqüências as regras da Antigüidade clássica, mas sem deixar de legar as suas criativas contribuiçōes para a nova estrutura sintática. No Tempietto, construído em 1502 no claustro de S. Pietro em Montorio, Roma, ele retoma o mítico tema do templo circular romano - cujo maior exemplo é o templo de Vesta, às margens do Tevere - e consegue uma surpreendente relaçāo entre o intercolúnio e o movimento circular de quem o contempla. Primeiramente, a cada coluna dórica colocada sobre o pódio que acessamos subindo três degraus, corresponde uma pilastra, também dórica, na parede do cilindro interior (a chamada cella). Os dois círculos concêntricos formados pelo perímetro da cella e pela planta do pódio que unifica as colunas, estāo numa proporção tal que se caminharmos pelo "corredor" circular existente entre eles, só poderemos ver, de uma só vez, apenas três colunas. Sempre. O intercolúnio corresponde exatamente a três diâmetros da base da coluna (diástilo), conforme já estava indicado também pelo número dos balaustres e pelas três métopas entre os dois tríglifos ${ }^{6}$ do friso do entablamento. Há aqui um elo mágico que aprisiona o corpo em movimento do observador no corpo da arquitetura, o que tentamos demonstrar com o croqui a seguir:

Agora se dirigirmos o nosso olhar para dentro, notaremos um outro ritmo no intercolúnio das pilastras (sístilo), dado pela colocação alternada entre nichos,
(4) Os tipos de intercolúnio foram registrados por Vitrúvio (primeiro quario do século I d C.): picnóstilo (espaçamento igual a uma vez e meia e altura igual a dez vezes o diametro das colunas), sistllo $(e=2 d ; h=9,5 d)$, éustilo ( $e=2.25 d ; h=9,5 d)$ diástilo $(e=3 d ; h=8,5 d)$ e araébstilo $(e=4 d$. $\mathrm{h}=\mathbf{8 d}$ )

(5) Corona, Lemos Dicıonário da Arquitelura Bra sileıra Săo Paulo: Edant, 1972, p. 324

(6) Segundo o glossárı publicado por SUMMER SON J In A linguagem clássica da Arquitetura. Sáo Paulo Martins Fontes, 1982), métopa é a área de forma quadrada "entre dois tríglifos no friso da ordem dórica" Normalmente náo é decorada, o que náo é o caso do Tempietlo. Triglı́fo é um elemento do friso da mesma ordem, "que possui dois sulcos verticais no meio e dois melos sulcos nas laterais. Acima do tríglıfo fica o mútulo e abaixo, as gotas. O conjunto é uma parátrase em alvenaria de componentes característicos da construçáo em madeira".

Fig. 1

Tempietto de San Pietro, em Moniorio. Roma, por Donato Bramante

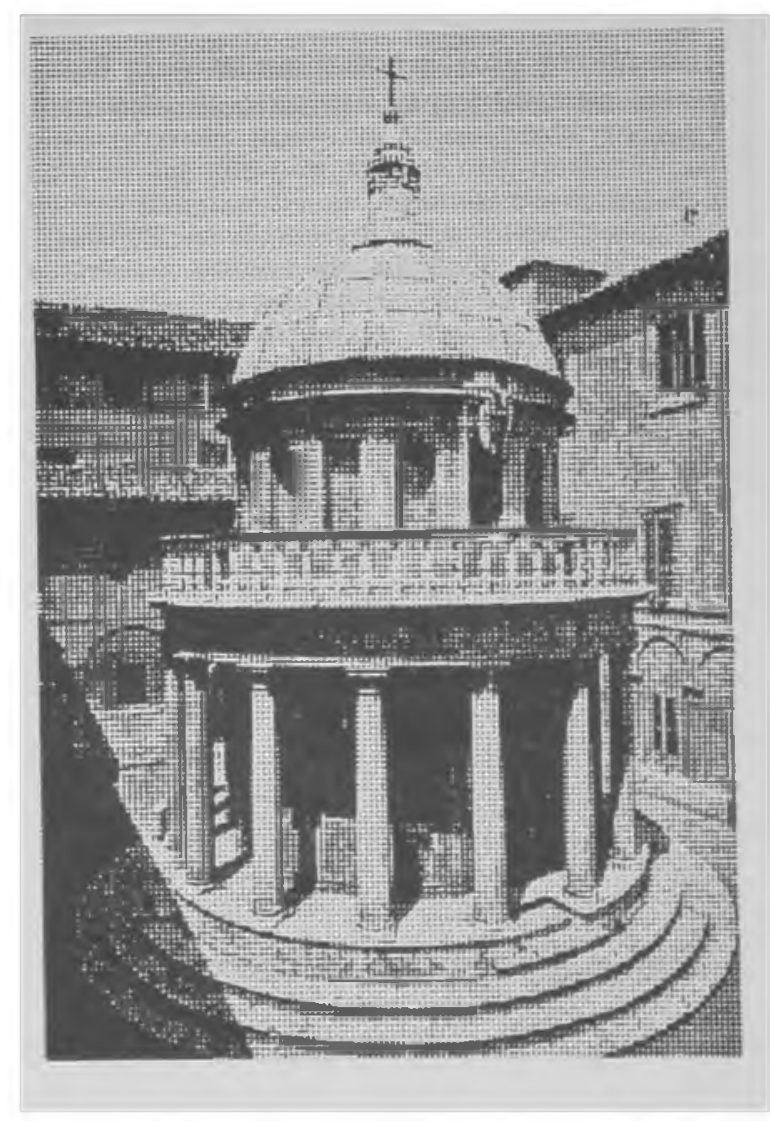

Pós - A Prog. Pós-Grad. Arquit. Ut FAlJusP São Paulo n 4 p. 107-112 dez 1993 
Fig. 2

Croqui do Tempietto de San Pietro.

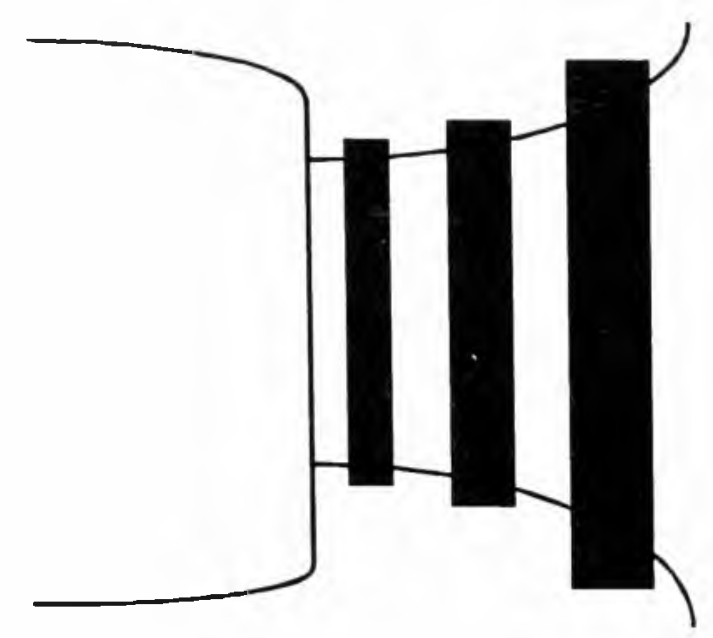

Fig. 3

Desenho realizado sobre a planta do Tempietto, recolhida por Palladio, in I Quattro Libri, IV. portas e janelas. O ritmo é assim: nicho - porta - nicho - janela - nicho - porta - nicho - janela ... Podemos também representá-lo assim: $n, p, n, j, n, p, n, j$, ... Quando nos deparamos com uma janela (ou uma porta aberta), notamos que a ela corresponde uma outra no lado oposto do templo, configurando um eixo de visão que ultrapassa duas janelas, possibilitando que vejamos o lado oposto do claustro. Vejamos esse diagrama, realizado sobre um desenho do Palladio:

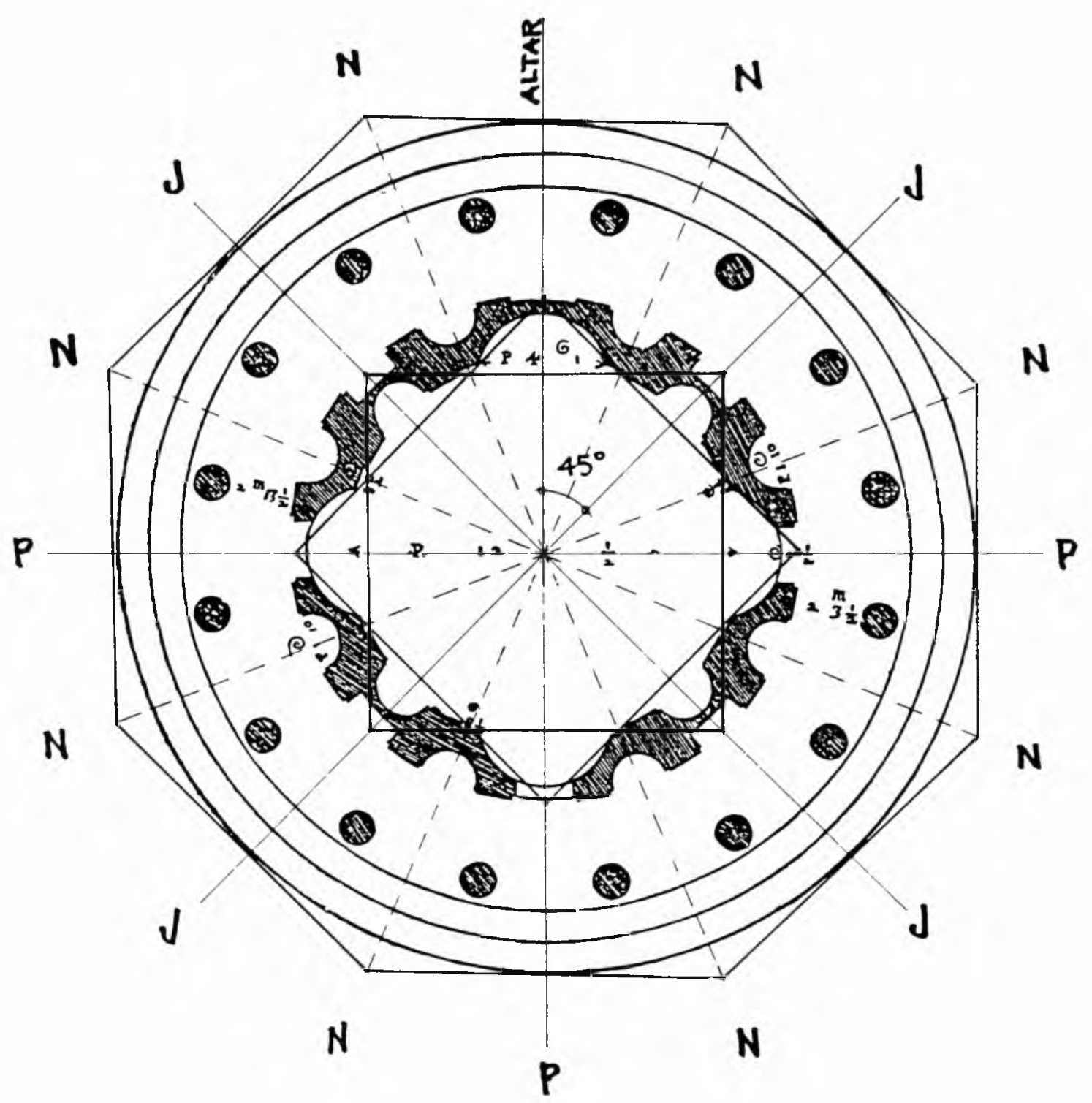

Traçamos na planta, o que o nosso olho e o nosso percurso, estava prestes a deduzir: obtivemos dois eixos perpendiculares formados por quatro janelas, dois outros formados pelas três portas e o altar, e mais outros quatro, não mais perpendiculares, mas a intervalos de 45 graus, formados por oito nichos. A uniāo entre os pontos marcados pelo centro das quatro janelas (onde passam os eixos) formam um quadrado. Analogamente, temos um outro quadrado para as três portas e o altar, e um octágono formado pelos oito nichos.

O Tempietto notabilizou-se pelo seu caráter inovador, mais especificamente pelo fato de Bramante ter dado continuidade ao cilindro interior, ultrapassando a altura das colunas e dos seus respectivos entablamento e balaustrada, coroando-o com uma cúpula. No interior do Tempietto, quando olhamos para cima, justamente para esta parte localizada acima do entablamento, notamos que sobre aquele quadrado imaginário que unia a porta principal colocada diante do altar e as outras duas portas laterais e opostas, desenha-se um outro quadrado formado por quatro janelas. Houve uma rotação de 45 graus entre o 

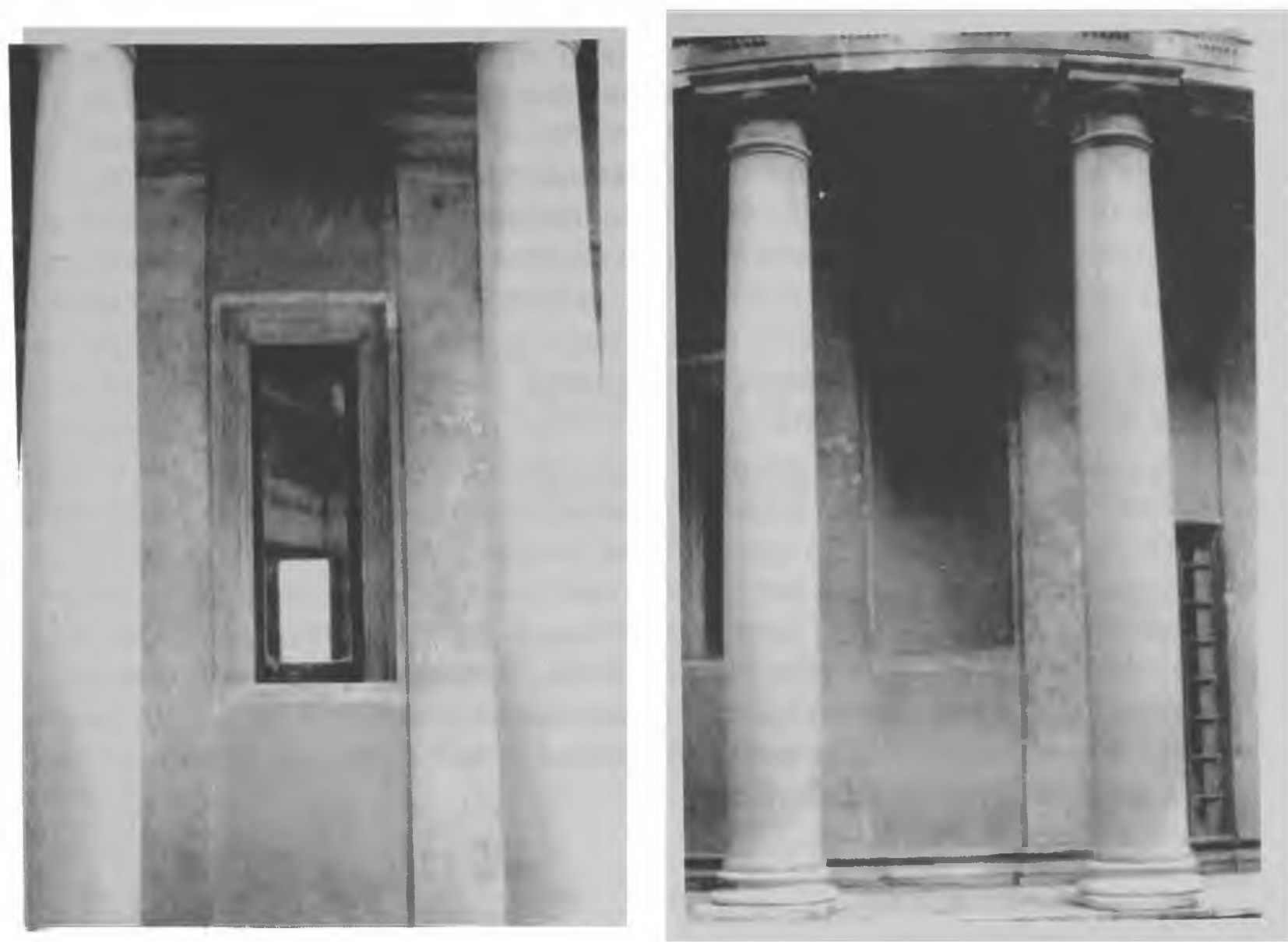

Fotos 1 e 2

Vistas externas do Tempietto.

Fotos: do autor

quadrado imaginário formado pelas quatro janelas inferiores e o quadrado formado pelas quatro superiores. Temos, portanto, oito janelas, dispostas sempre em pares frontais, remetendo à forma do octágono, dada pela rotação do quadrado. O tema da quadratura do círculo ${ }^{7}$ é trabalhado aqui através da disposição das janelas e dos nichos ("falsas janelas"). A janela permite o diálogo entre o interno e o externo. O nicho, com a imagem santa, coloca o fiel em contato com o que ela representa. Diálogos entre Homem e Deus, entre círculos e quadrados.
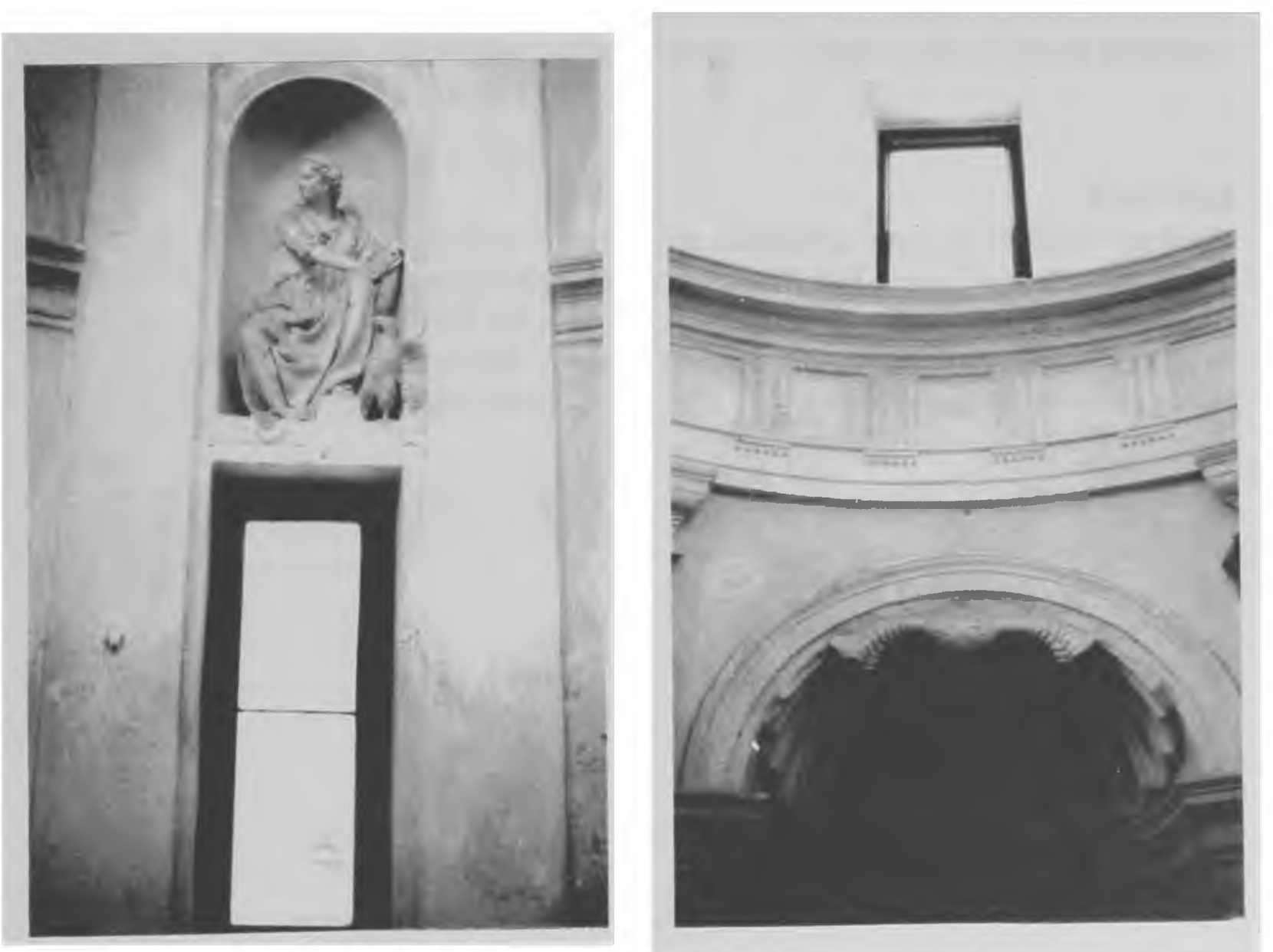

(7) Era comum a utilizaçăo da forma octogonal para as pias batismais ou para os próprios corpos dos batistérios na construçâo das antigas catedrais. O octágono é resultanle da intençấo de encontrar a soluçáo para o problema da quadraura do círculo, ou seja o de construir com régua lura do circulo, oc seja, o de construir com ígua e compasso, um circulo e um quadrado com mesma superfície Vejamos o que nos diz Pierantoni (in El ajo y la idea. Fisilogla e historia de la visión. Barcelona, Paidós, 1984, p. 140): "A soluçăo não é possivel mas lentar a busca é irresistivel. Uma das aproximacós geométricas mais fascinantes é a que leva a const meiro se constroi um quadrado. Depois inscrevese um círculo no quadrado, islo é, fazendo que os lados do quadrado tangenciem seus pontos médios E obvio que a area do quadrado excede a do circulo nas qualro superlicies triângulares de base curvilineas, limitadas pelos lados do quadrado e da circunferência inscrita. Agora expande-se o circulo lentamente. Pouco a pouco a circunferência ultrapassará os lados invadindo o plano além do perímetro do quadrado. Pode-se sonhar com um inefavel momento no qual a superficie das quatro luas (aureolas que excedem a superfície do quadrado) e os quatro triângulos curvilineos estejam em equilíbrio Se unirmos os pontos de intersecçăo do círculo e o quadrado obteremos um octágono. Portanto, o octágono representa o ponto de encontro, a estrutura intermedíria entre o circulo que representa o infinito. que por sua vez, representa mundo" O octágono é o sublime ponto de tangência entre o divino e o humano, fonte de eterna salvaçăo.

Fotos 3 e 4

Vistas internas do Tempietto (detalhes)

Fotos: do autor 
Se externamente a janela apresentava uma moldura que preenchia o espaço entre a abertura propriamente dita e as pilastras, internamente, pelo fato de ser o circulo de diâmetro menor, ela praticamente encosta nas pilastras, assumindo a tarefa de indicar (até mesmo pela verticalidade da sua forma) o nicho com a imagem situado sobre ela. Bramante demonstra-nos a possibilidade de construção, explicitação e contemplação de uma lógica eminentemente visual, onde a janela protagoniza um papel de extrema delicadeza. O nosso olho o deduz. O nosso espírito extasia-se ao imaginar que estávamos diante de um decisivo passo na sintaxe arquitetônica: uma poética clarificadora, que nos ensina a olhar. uma transparência que corrige o percurso da luz, apontando com a precisão geométrica os alvos que cuidadosamente seleciona, o olho obedece o pensamento e a luz que penetra pela janela nos apresenta a mais verdadeira das belezas: não são mais as imagens postas nos nichos, nem o altar, mas a obra do homem em contato com a verdade divina. Não há vitrais, nem óculuns, mas janelas, com sua prosaica transparência, ofertadas aos olhos dos fiéis. Transcendental transparência Bramante constrói uma dessas máquinas para o olho. um instrumento a serviço da visão, que faz do ato de ver um ato de conhecer O Tempietto já insinua a autonomia do signıficado da janela na linguagem da arquitetura. 